\title{
THE COACH-PARENT RELATIONSHIP IN JUVENILE FOOTBALL
}

\author{
Gheorghe GRIGORE ${ }^{1}$, Sorin CIOLC $\breve{A}^{1}$, Tudor PALADE ${ }^{1 *}$ \\ ${ }^{1}$ National University of Physical Education and Sport, Faculty of Physical Education and Sport, Bucharest, Romania \\ *Corresponding author: paladetudor@yahoo.com
}

DOI: $10.35189 /$ iphm.icpesk.2019.15

\begin{abstract}
In current juvenile football, the coach-parent relationship is an important and delicate issue, because both of them are actively and directly involved in the growth and development of future football players. Problematic situations that occur in the training process, during the game and extra sports activities are determined by the different perspectives of addressing all the problems encountered. Collaboration between coaches and parents effectively contributes to both the training of a future football player and his education in the social context. Communication between these factors is extremely important as it helps the coach to collect relevant information about the child's temperament, character, behaviour and habits. Discussions with parents should be permanent and transparent and aimed to solve existing problems. Our scientific approach consisted in applying questionnaires to both coaches and parents in order to highlight the factors that influence this relationship and the distinct roles played by the two parties involved. The questionnaire items refer to the behaviours of coaches and parents in formal training sessions and during games, the willingness of both parties to achieve effective information feed-back and the establishment of an ideal coach-parent model. The conclusions drawn from this study can contribute to optimising the coach-parent relationship, which would lead to the psychosocial and athletic development of future football players.
\end{abstract}

Keywords: coach, communication, football, parent.

\section{Introduction}

The development of the football game has now reached a level that few people could have imagined. The question we want to answer is: "What will be the level to be reached in the future?" We do not know, but, in this research, we aim to address one of the disrupting factors that often stagnates the athletic evolution of players. We are referring here to the coach-parent relationship whose central element is the child as a future football player.

Among the positive attitudes that can be encountered in sports, we mention: cooperation for progress with all the factors involved in training, cooperation with the competition partners and cooperation with the coach (Badea, 2016, pp. 16-17).

The role of the coach working with juvenile players is particularly complex, because he has to manage, besides the training process, the relationship with the parents of players in order to achieve superior results on each formative level. The coach-parent relationship should be constructive with a view to positively influence the evolution of future football players.

Bichescu (2013) states that the difficulty of this relationship is determined by the rather large and different range of temperaments, characters and levels of education the coach has to deal with, but also the various concepts about football and training that more and more parents begin to express.

According to Geambaşu (2018, p. 150), communication is a basic goal of a successful motor action. The verbal or nonverbal feedback provided by the athlete during or outside training allows calibrating the physical effort and the instructions and encouragements provided by the coach.

This scientific paper is focused on three main directions of addressing the coach-parent communication. We are referring here to issues arising from the limitations, rules and mistakes encountered in this relationship, which represent important benchmarks in the process of growth and formation of the football player.

Parents are not supposed to assume the role of a trainer or coach, but to provide the psychological and material support necessary for the further development of the child. This approach should not be seen as a limitation of the family role, but as a reassertion of its importance in the bio-psycho-social development of the young footballer.

On the other hand, the coach should accept permanent collaboration with parents and consider them as partners rather than opponents throughout the long-term process of child formation, from an athletic point of view.

For example, Clarke and Harwood (2014) have explored the phenomenon of being the parent of a young footballer at an academy and conclude that this can be both challenging and complicated. Specifically, parents described reassessing their role as parents of an elite athlete, which was associated with an enhanced status, but also heightened concerns regarding the potential negative consequences for their children and a need to protect them from harm. Parents also described having to learn about the social and organizational expectations of the environment associated with increased time and monetary investment, but also a decrease in their role as they hand 
over responsibility to coaches and are asked to stay detached from their children's experience. As parents attempt to negotiate these changes and challenges, one could see how they might "get it wrong" and find their involvement to be less than optimal.

We believe that the development of an Internal Regulation by the leadership of all football clubs/schools/ academies, in collaboration with coaches and with the signature of parents, would be important. This is supposed to delimit their behaviours and attitudes in both the training process and competitions.

Regarding the common mistakes made by the two parties involved in the specific activity, it is highlighted the keen desire to see the children progress much too quickly and achieve results by all means to the detriment of complying with the requirements of the training stages. Also, frequent participation in a large number of competitions from an early age and without an appropriate support of the training methodology contribute to deepening some physical and technical tactical gaps.

All these issues should be discussed during meetings with parents, although sometimes discussions are problematic and stressful for the coach.

Successful coaches are aware of the importance of securing the aid and support of well-informed parents. Rather than facing the task of dealing with problem parents, a pre-season meeting is the key to reducing the chance of unpleasant experiences (Smoll, Cumming, \& Smith, 2011).

\section{Problem statement}

The tasks of this scientific approach were to highlight:

- Specific objectives of juvenile football;

- Parent responsibilities and expectations;

- Optimal communication between parent and coach.

\section{Research questions}

As regards the research on the coach-parent relationship in juvenile football, the following questions arise:

- Can we identify the organizational aspects relating to parent involvement in training and games by applying a questionnaire?

- Do the questionnaire responses allow us to establish the essential benchmarks underlying the coachparent communication?

\section{Purpose of the study}

The research aims at finding new ways to make the coach-parent relationship more efficient, with positive effects on the training process of children and junior football players.

\section{Material and Methods}

The research subjects are 59 coaches and 76 parents.

To carry out the research, we used the following methods: observation, questionnaire survey, mathematical and statistical processing and graphical method.

Instruments: to solve the research issues, we used a questionnaire consisting of 11 items (6 with predefined responses, 4 mixed and 1 with an open response) addressed to both coaches and parents.

We present below the questionnaire items.

- Questionnaire for coaches

1. At the club where you work, is there a Regulation on parent activity? (a. Yes; b. No), 2. At the club where you work, are parents allowed to be present at your training sessions? (a. Yes; b. No), 3. But at the games played by children? (a. Yes; b. No), 4. What are the most usual behaviours of parents during training? (a. Give verbal indications; b. Give indications by gestures; $c$. Enter the field if the child gets injured; d. Have proper behaviour; e. Other), 5. But during games? (a. Give verbal indications; b. Give indications by gestures; $c$. Enter the field if the child gets injured; d. Offend the referee; e. Offend the opposing team players and their parents; f. Have proper behaviour; g. Other), 6. At the coach-parent meetings, are parents cooperative/involved in discussions? (a. Yes; b. No), 7. Are they open to the coach's proposals on improving the activity? (a. Yes; b. No), 8. Do you think that the team's group of parents is a cohesive one? (a. Yes; b. No), 9. What types of information should be provided to parents? (a. information on the biological component - hygiene, nutrition); b. information on the psychological 
component; c. information on the technical tactical component; d. other information), 10. Who do you think has a more important role in child education? (a. Parent; b. Coach; c. School; d. Other factors), 11. What do you think would be the ideal qualities of a parent?

- Questionnaire for parents

1. At the club where your child plays, is there a Regulation on parent activity? (a. Yes; b. No), 2. Are you allowed to be present at the training sessions of your children? (a. Yes; b. No), 3. But at the games played by children? (a. Yes; b. No), 4. How do you behave during training? (a. Give verbal indications; b. Give indications by gestures; c. Enter the field if my child gets injured; d. Have proper behaviour; e. Other), 5. But during games? (a. Give verbal indications; b. Give indications by gestures; c. Enter the field if my child gets injured; d. Offend the referee; e. Offend the opposing team players and their parents; f. Have proper behaviour; g. Other), 6. At the coach-parent meetings, are you satisfied with the communication between you and the coach? (a. Yes; b. No), 7. Are you open to the coach's proposals on improving the activity? (a. Yes; b. No), 8. Do you think that the team's group of parents is a cohesive one? (a. Yes; b. No), 9. What types of information do you consider necessary for good sports training? (a. information on the biological component - hygiene, nutrition); b. information on the psychological component; c. information on the technical tactical component; d. other information), 10. Who do you think has a more important role in child education? (a. Parent; b. Coach; c. School; d. Other factors), 11. What do you think would be the ideal qualities of a coach?

Procedure: the questionnaires were hand scored and lasted about 10 minutes.

\section{Results}

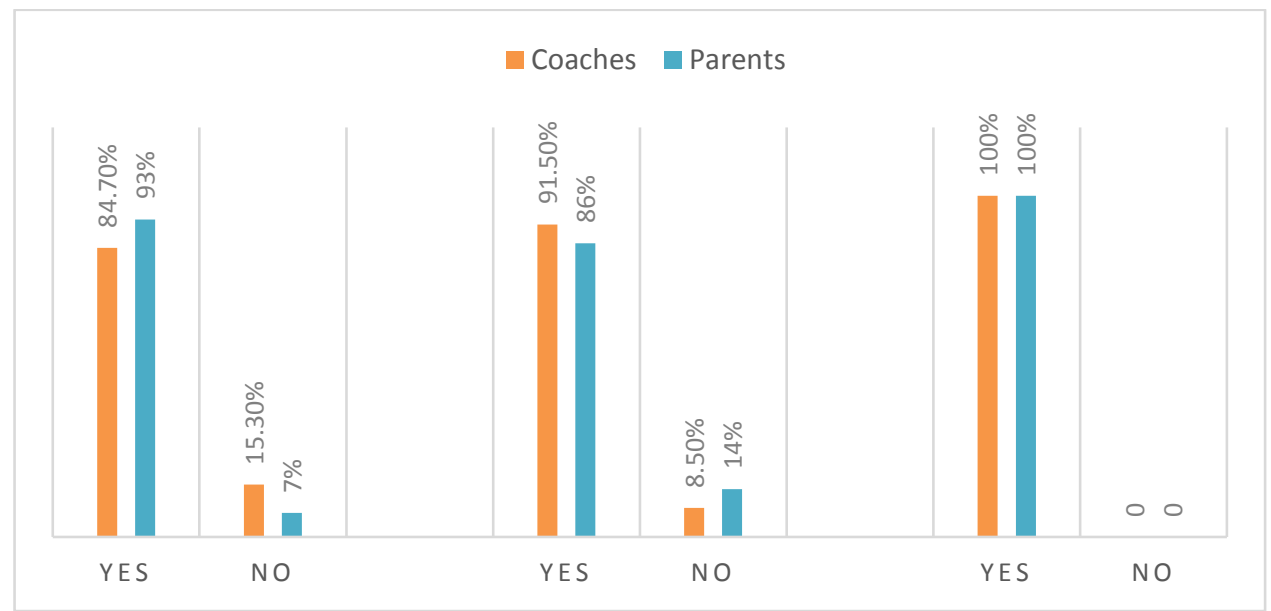

Figure 1. Percentage representation of responses to Questions 1, 2 and 3

Regarding the responses to Questions 1, 2 and 3 (Figure 1), we mention:

- For Question 1, positive responses have a considerable percentage ( $84.7 \%$ and 93\%), but we notice that there are clubs where such a Regulation does not exist;

- For Question 2, we notice that most clubs allow parents to be present at the training sessions of their children (except for FCSB and Dinamo);

- For Question 3, responses are unanimously positive, all clubs allowing parents to be present at the games played by their children. 


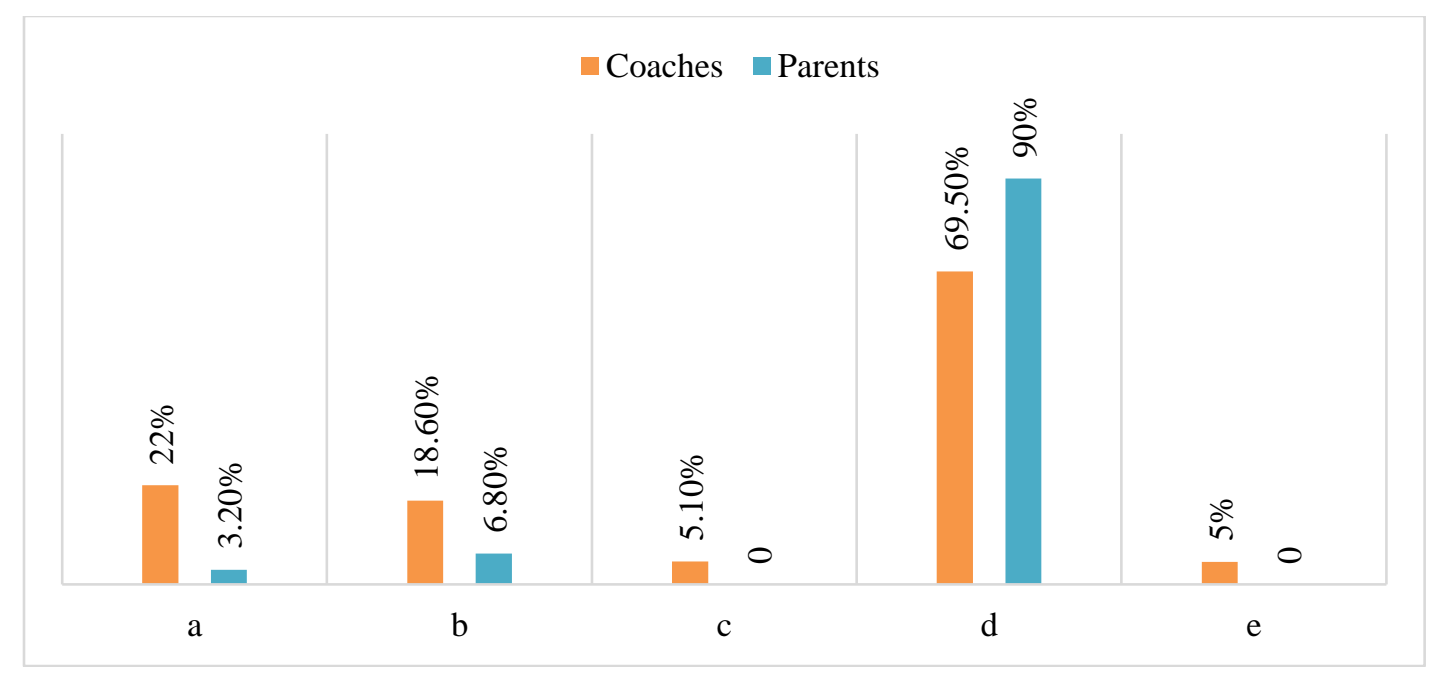

Figure 2. Percentage representation of responses to Question 4

For Question 4 regarding the parent behaviour during training (Figure 2), a significant difference in perception can be noted, as follows:

- Most parents (90\%) report they have proper behaviour, while only about $70 \%$ of coaches agree to this statement. The $20 \%$ difference in perception demonstrates that often, from a desire to help their children, parents interfere with the work of the coach;

- The negative behaviour claimed by coaches includes $22 \%$ verbal indications and about $19 \%$ non-verbal indications.

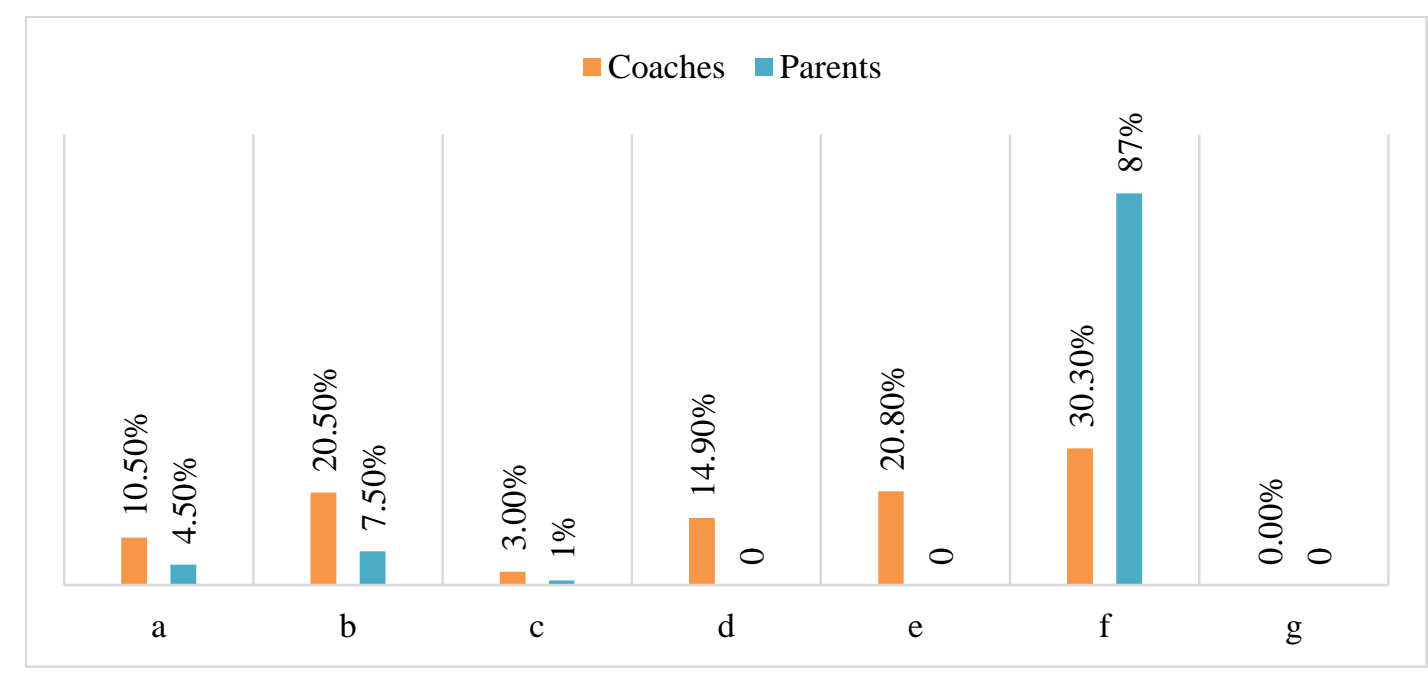

Figure 3. Percentage representation of responses to Question 5

Differences between the opinions of coaches and parents (Figure 3) related to the behaviour of the latter during games are very large $(30.3 \%$ vs. $87 \%)$, which indicates that all these represent a normality factor for some and a disruptive factor for others. Even if coaches mainly focus on the game play, their responses reveal that they are aware of the inappropriate interventions of parents (verbal and gestural indications, offenses). 


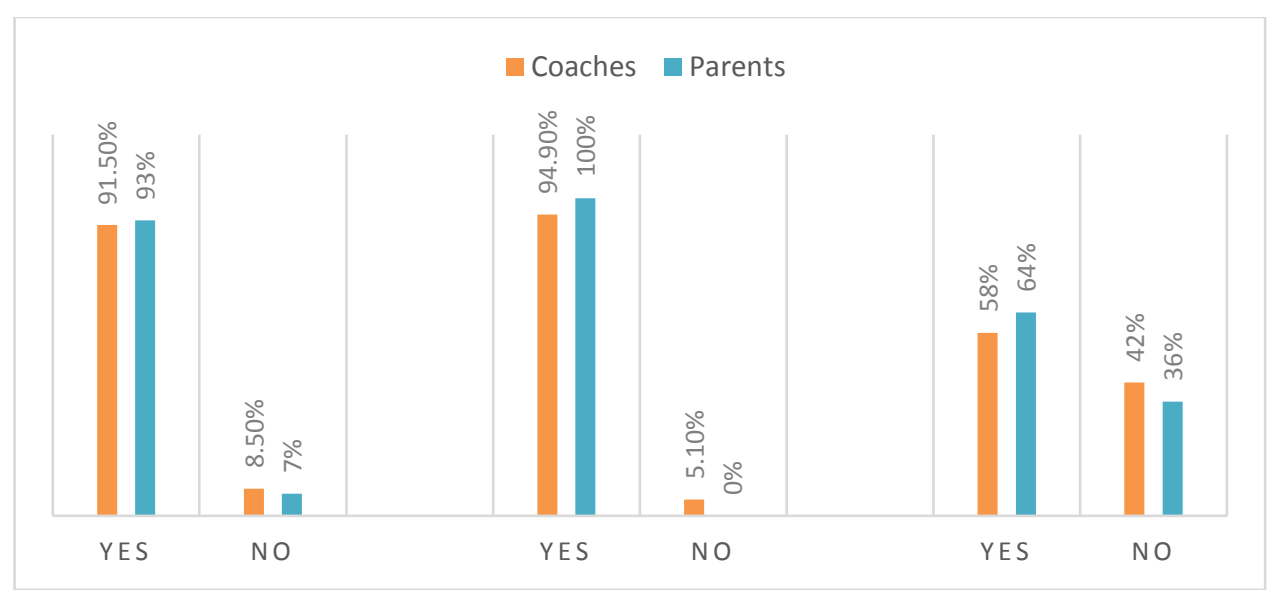

Figure 4. Percentage representation of responses to Questions 6, 7 and 8

Although the previously analysed questions highlight a major difference in perception, the responses to Questions 6 and 7 (related to coach-parent meetings) converge almost unanimously to the same optimal area as regards communication between them.

In terms of group cohesion (Figure 4), the results indicate partial cohesion between parents, and coaches perceive this issue almost similarly, but this might be a disrupting factor in the achievement of positive results.

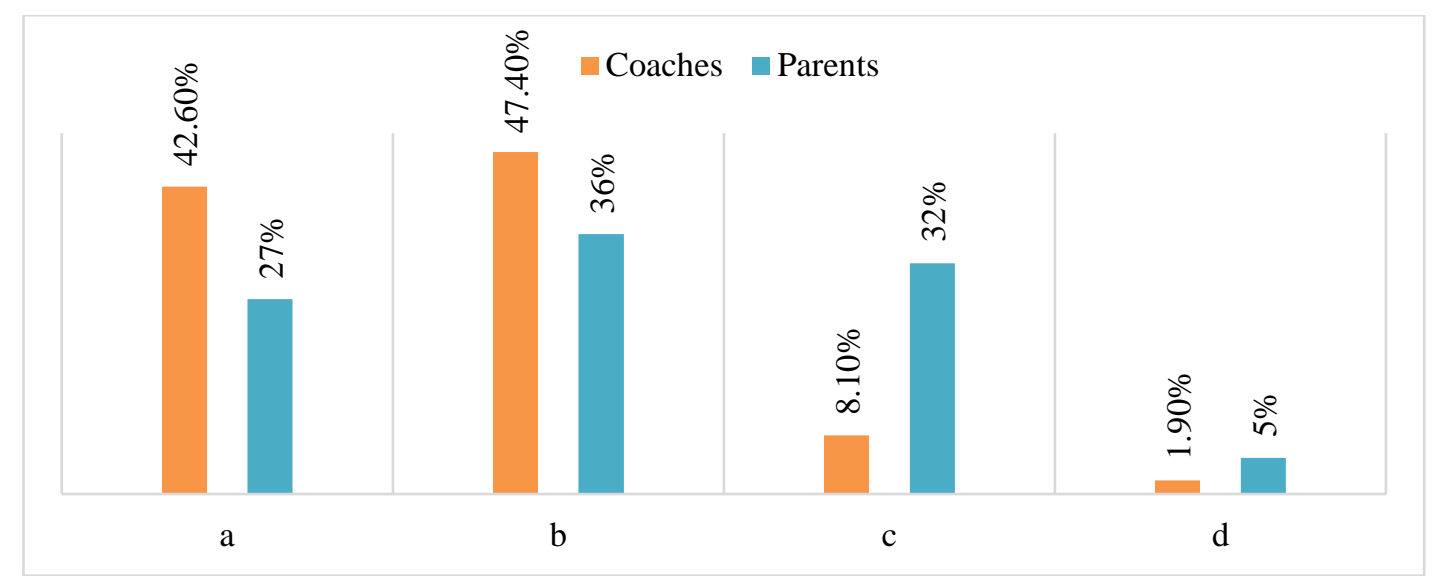

Figure 5. Percentage representation of responses to Question 9

The responses to Question 9 (Figure 5) indicate that parents want more information about the technical tactical component than they are provided (32\% vs. $8.1 \%)$, while coaches believe that references about the psychological component are the most important for the proper development of the child (47.4\% vs. $36 \%)$.

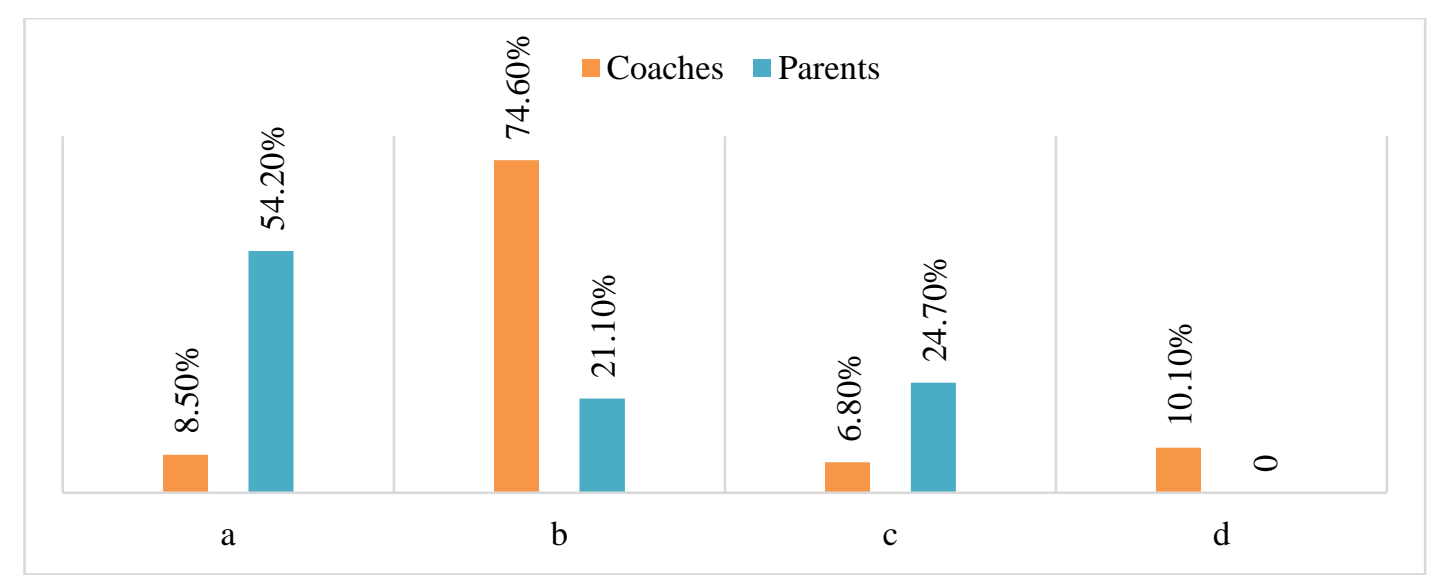

Figure 6. Percentage representation of responses to Question 10 
The responses to Question 10 (Figure 6) reveal significant differences in perception between coaches and parents as regards the decisive role in child education, each of the two parties claiming to play the key role in their formation. At the same time, the above figure highlights a significant difference (24.7\% parents vs. $6.8 \%$ coaches) concerning the role played by the school in the instructive-educational process.

Analysing Question 11 (where each subject responded according to personal views), we notice the following:

- For parents, the main qualities of a coach converge to the area of assertive behaviour, where understanding, openness and closeness to children are defining features;

- For coaches, the predominant qualities of a parent are related to the motivational area (to support, encourage and be lenient with children).

\section{Conclusion}

The coach-teacher relationship influences sports performance as follows:

- Verbal and gestural indications, as well offenses to the referee or the opposing team players and their parents, are a reality in current juvenile football, with negative consequences on the psycho-pedagogical level. This situation is likely to be transferable to the behaviour of children in both their sports activity and daily conduct.

- Lack of cohesion in the relationships between parents and coach-parents can lead to a hostile attitude of the child within the group and a possible decrease in the team's performance;

- In a competence-based community, the school is the main provider of education, regardless of the field of activity concerned. For this reason, we think that the responses given by the surveyed subjects are not in a proper direction for the development of society.

The coach-parent relationship should be seen as a harmonious balance with the child in its centre, and any attempt to exacerbate the influence of one of the parties will lead to the impossibility of achieving the potential of the future performer.

\section{References}

Badea, D. (2016). Teoria antrenamentului sportiv și competiției [Theory of sports training and competition]. București: Discobolul.

Bichescu, A. I. (2013). Fotbal: Strategia instruirii în centrele de copii şi juniori [Football: The training strategy in children's and junior centres]. Timişoara: Editura de Vest.

Clarke, N. J., \& Harwood, C. G. (2014). Parenting experiences in elite youth football: A phenomenological study. Psychology of Sport and Exercise, 15(5), 528-537. https://doi.org/10.1016/j.psychsport.2014.05.004

Geambaşu, A. (2018). Metode și tehnici de tonifiere musculară [Methods and techniques of muscle toning]. București: Discobolul.

Smoll, F. L., Cumming, S. P., \& Smith, R. E. (2011). Enhancing coach-parent relationships in youth sports: Increasing harmony and minimizing hassle. International Journal of Sports Science \& Coaching, 6(1), 1326. https://doi.org/10.1260/1747-9541.6.1.13 